\title{
Stem Cells Promise Reality and Controversy
}

\author{
Aftab Ahmed, PhD \\ Peoria, Illinois
}

$\mathrm{H}$ ardly any advance in modern science has generated so much more heat than light than the advances related to stem cell research. The chasm between proponents and opponents of stem cell research could not be more cavernous despite the fact that the potential of stem cells is yet to be fully realized. Fundamentally, however, the acrimony in the wake of discussions on stem cells is not solely a feature of our contentious era. For example, in the 11th century, treatment of illness with medicine was deemed to violate the Holy Writ, and the use of chloroform as an anesthetic in the 18th century was seen as a "satanic invention." Equally, in his day, Edward Jenner was characterized as "a presumptuous man" by newspapers, while religious authorities considered inoculation against smallpox an affront to God and man. ${ }^{1}$ Not even the superfecund imagination of a science fiction writer or a conniving political operator could have conjured up a conflict to the extent that the issue of stem cells seemingly has. The question revolves around what stem cells are, of what promise they are a harbinger, and what impediments lie on the path to the realization of their potential. It is quite timely, then, that in this issue of JIMA, Dr. Hossam Fadel discusses stem cell research at length. In his review, Dr. Fadel addresses the scientific underpinnings of this research and discusses ethical issues and religious points of view regarding this research, specifically from the perspective of Islam. ${ }^{2}$

Stem cells (SCs) may be described as master cells. One of these master cells, upon fertilization of an ovum, begets nearly 100 trillion cells in the case of humans, divided into some 250 cell families that make up the human body. Cells in these families can

Dr. Aftab Ahmed is the CEO of Bio-Aging, Inc. in Peoria, Illinois. Correspondence may be sent to aftabahmed@msn.com. replace themselves as needed, some noticeably such as, cells of the skin, hair, and bone marrow while others do so more subtly. Stems cells provide a ready reservoir to sustain life, as they are found throughout the body, typically in niches proximal to specialized cells, called nurse cells, which provide growth factors and other signaling molecules. Stem cells are capable of self-renewal and produce unaltered daughter cells but, equally, have the ability to produce daughter cells that have different, more restricted properties. ${ }^{3}$

Depending upon the stage of development, mammalian SCs can be totipotent, pluripotent, or multipotent. Thus, the zygote is considered a totipotent SC, as it has total potency - i.e., the potential to become an entire individual of a species. As such, totipotent cells have an unbounded "stemness." 4 In the first hours after fertilization, this cell (the zygote) begins to divide into identical totipotent SCs. Four days postfertilization, totipotent SCs begin to specialize, forming a blastocyst, a hollow ball of cells. The blastocyst's outer wall is the trophoblast, and its inner wall is known as the inner cell mass (ICM). The ICM harbors tissue-specific embryonic SCs (ESCs). These ESCs are destined to form most of the cells, tissues, and organs in the body.

These ESCs are pluripotent, as they are preprogrammed and lack the wherewithal to develop into an entire organism. ${ }^{5}$ It is these ESCs that are the subject of intense scientific and lay debate. The only sources known to date of ESCs are those harvested from early human embryos and from fetal tissue that was destined to be part of the gonads. In contrast, multipotent SCs come from mature tissues, including bone marrow, blood and, among others, skeletal muscle.

The excitement and consternation of the use of ESCs emanates from the fact that they are literally nature's blank slate. The source of both the hype and 
admonition on the use of ESCs rests on their plasticity. That is, their ability to divide continuously and develop into a wide variety of cell types, showing patterns of gene expression characteristic of undifferentiated cells. 6,7 Under certain conditions that are neither yet fully known nor fully controlled, ESCs undergo differentiation into endoderm (e.g., gut epithelium), mesoderm (cartilage, bone and muscle), and ectoderm (skin). With such prospects, as if out of the blue, the grim roll call of irreversible diseases now looks more promising. Given this potent blend of hope, scientific/clinical applications, political sensitivity and, not least, commercial possibilities, it is a small wonder that the potential of stem cell therapy has been exaggerated and, in equal measure, dismissed.

To achieve these objectives, while obviating the ethical minefield of harvesting human embryonic stem cells (hESC) from fertility clinics or terminated fetuses, custom-fertilization and therapeutic cloning are being pursued as sources of these cells. In customfertilization, embryos are created specifically to fertilize an ovum with the seminal fluid to harvest ESCs. In therapeutic cloning, stem cells are cloned from adult donor cells by somatic-cell transfer. ${ }^{2}$

Therapeutic cloning got a substantial boost when it was reported in 2004 that a South Korean research team had created patient-specific stem cells. ${ }^{8}$ Despite the known challenges inherent in such an endeavor, this was hailed worldwide as a seminal breakthrough. The ugly truth, however, was that the claim to have successfully cloned SCs was a well-contrived hoax. Questions about its success began almost immediately after the announcement with the purported unethical means to obtain eggs for cloning, and the entire research was quickly deemed to have been an elaborate fraud. ${ }^{9}$

The setback notwithstanding, however, this unsavory episode seems to have galvanized interest in therapeutic cloning afresh. Despite the falsity of the research, this report on therapeutic cloning provided a glimpse to those initiated in the field as to what might be possible with cloned SCs and has reinvigorated interest in therapeutic cloning. Thus, cloned SCs could be used as model systems to study human disease and test new drugs with unprecedented accuracy. By the same token, if ESCs could be coaxed to differentiate along specific lineages, they could be transplanted directly into patients to cure degenerative diseases. It has already been shown in animal experiments that ESCs can help treat heart disease, spinal cord injury, and sickle cell anemia. Before such therapies can be tested in patients, however, the issue of graft rejection would have to be resolved satisfactorily. The more promising approach to make ESCs suitable for transplant would be therapeutic cloning, which is years away at best.

One example to exploit the unparalleled pliancy of ESCs would be to correct any genetic defects before transplantation as in the case of patients with LeschNyhan syndrome, in which genetic mutations result in excess uric acid production and its accumulation in the tissue, leading to neurological problems.

Inasmuch as such prospects have captivated the lay imagination, the broader implications of this research are intriguing and, importantly, are closer at hand. Instead of using the cells as a therapy in of itself, researchers are planning to use them to evaluate new treatments. One of the ramifications would be an improved understanding of the natural history of diseases with genetic components at the cellular level.10

For instance, a SC line mimicking Parkinson's disease (PD) could be developed with the DNA from patients with its symptoms. Stem cells could be prodded to develop into the type damaged by a given disease. In the case of PD, dopamine neurons could be manipulated to study its course of progression from the earliest stirrings to its final stage. Since the cells would be genetically identical to that of the patients, by and large, they are expected to undergo the same molecular changes underlying the disease processes in vivo. Once these kinds of disease models come to fruition, they are more likely to help develop effective therapies than therapeutic cloning or customfertilization. Cloned SCs would allow a clearer understanding of what the disease does before its symptoms manifest. Currently, treatments are geared more towards the body after the damage has already been done. In a sense, it is akin to resurrecting the wreckage after an airplane has hit the ground. After all, critical to an effective therapy is the question: What happened before the crash?

It should be pointed out, however, that cloned SCs are rather difficult to make. First, it is not clear how many human eggs would be required, or how many women would voluntarily agree to donate them. Second, harvesting of eggs is a painful procedure, which in a percentage of donors causes ovarianhyperstimulation syndrome and can result in kidney 
failure, albeit in rare instances.

It is against this backdrop, combined with the sticky issues related to the use of human embryos, that the debate on the use of ESCs is presently framed. Consequently, the ethical thicket has spawned greater attention to multipotent adult stem cells. Hence, efforts are underway to reprogram adult SCs (ASCs) to revert to their embryonic state. Reversion from the differentiated phenotype to the embryonic state depends upon transcriptional activity in a given cell type. Transcriptional controls function as genetic switches to reprogram the cellular fate, but it is a poorly understood transformation that takes place during cloning. ${ }^{11,12}$

This approach predicates the pattern of gene activity in a cell and determines whether it will become a SC or differentiate along a particular lineage. Reprogramming of an adult stem cell to its embryonic cognate is largely a toss-up, as still unknown factor(s) deactivate(s) genes to make a cell a myocyte, say, or activate those expressed in an embryo.

Accomplishment of this feat would be a significant development. In fact, such understanding could usher in new technologies to revert adult cells directly into embryonic cells, eliminating the controversy surrounding hESCs. In its wake, a new era in regenerative medicine could well dawn and free hESCs from moral and ethical quandaries. Nuclear transfer, however, is the only technique presently available for reprogramming. If it is scuttled, the imbroglio stands only to prolong the vexing debate on hESCs.

Human embryonic stem cell research is teeming with issues and challenges - scientific/clinical, ethical, moral, and philosophical - that must be addressed in order for its potential to be fully harnessed. The words that are chosen to drive the discussion, however, reveal the mental universe the society inhabits. Worse yet, with each round of argument, the questions central to hESC research get buried under further layers of rhetoric and confusion. The political posturing on either side makes it difficult to discern what the debate is really about. It is not about ethics, for there are ethical and unethical ways to do research; nor is it about whether there ought to be ethical limits on scientific research. There is a broad consensus that research involving human subjects should have strict limits. So, then, is the question whether embryos are such human subjects? In turn, this does not suggest, however, that the debate is about when human life begins, as it does not settle the debate, for human life begins when the embryo is created, and it is human and alive.

This line of reasoning does away not only with biology as noted above but also with politics. How so? At the core of the debate is the question whether a human embryo - microscopically small with no selfawareness - is a person with a right to life. Proponents of hESC research answer this question negatively, arguing that it is but a "clump of cells" with no discernible characteristics that comprise human life. This argument begs the question, however, since the society would not deny those who have lost some mental faculties the inherent right to be regarded with respect and protected from harm. Why, then, should it be denied to those whose faculties are still being developed?

Thus, biology and common sense alike stipulate that at issue is whether all human life is equal. The circumstance of the embryo outside the mother's body puts the question rather dramatically, but it does not change the question. Prima facie the intrinsic equality and worth of human life is incontrovertible, as intoned in the Holy Quran: "We have honored the sons of Adam:" (17:70). Pragmatically, however, many argue that the benefits, which hESCs promise to yield, far outweigh the limo-like life of unwanted embryos in storage in liquid nitrogen. To counter this, abstract moral principles - as whether noble ends justify ignoble means must be calibrated against concrete circumstances and anticipated outcomes.

The real concern in this slippery slope is perhaps the irresistible temptation to commodify human embryos. After all, the interested parties are not isolated individuals, arguing over a "right to choose" as with abortion. Equally, the beneficiaries are not the sick, the aged, and prematurely infirm. Those who will benefit from the technology are, first and foremost, the universities, pharmaceutical firms and, indeed, the federal government in the race to market therapies for degenerative diseases. ${ }^{13}$

In a broader context, society must grapple with the possibility of humanity eventually reinventing itself. This calls for prudence and wisdom, neither in ample supply in the hESC debate. Implicit in such considerations is what is meant by human life and progress. This is the underlying proposition in the 
hESC debate, and it will become further entangled as biotechnology progresses apace. The debate on hESCs should be the first and, by all indications, the easiest. For at this juncture, the choice is not between science and a compassionate society. Rather, the challenge is to champion both, as moral sincerity and/or convictions are not impressive, if they are dependent upon willful ignorance and indifference to logic.

\section{References}

1. Blum DA. Pox on Stem Cell Research. The New York Times, 2006 Aug 1;Sect. A:11. Available from: http://www.nytimes.com/2006/08/01/opinion/01bl um.html?ex=1176004800\&en $=72 f 5 c 515 b 65650 a 9 \&$ ei $=5$ 070.

2. Fadel HE. Stem cell research. Prospects and ethics: an Islamic perspective. J Islam Med Assn. 2007;39:7383.

3. Tabibzadeh S, Hemmati-Brivanlou A. Lefty at the crossroads of "stemness" and differentiative events. Stem Cells. 2006 Sep;24(9):1998-2006.

4. Bilodeau M, Sauvageau G. Uncovering stemness. Nat Cell Biol. 2006 Oct;8(10):1048-9.

5. Hochedlinger K, Jaenisch R. Nuclear reprogramming and pluripotency. 2006;441(7097):1061-7.
6. Lewis R. Stem cells... an emerging portrait. The Scientist. 2005;19(13):14.

7. Vogel G. Stem cell research. Four genes confer embryonic potential. Science. 2006;313(5783):27.

8. Hwang WS, Roh SI, Lee BC, et al. Patient-specific embryonic stem cells derived from human SCNT blastocysts. Science. 2005 Jun 17;308(5729):1777-83. Retraction in: Kennedy D. Science. 2006 Jan 20;311(5759):335.

9. Cho MK, McGee G, Magnus D. Research conduct. Lessons of the stem cell scandal. 2006;311(5761):614-5. 10. Geraerts M, Krylyshkina O, Debyser Z, et al. Concise review: therapeutic strategies for Parkinson disease based on the modulation of adult neurogenesis. Stem Cells. 2007;25(2):263-70.

11. Richards M, Tan SP, Tan JH, et al. The transcriptome profile of human embryonic stem cells as defined by SAGE. Stem Cells. 2004;22(1):51-64.

12. Scadden, DT. The stem-cell niche as an entity of action. Nature. 2006;441(7097):1075-9.

13. Sinskey AJ, Finkelstein SN, Cooper SM. The consequences of limiting stem cell research: health and economic considerations. Pharmaceutical Discovery. 2005;5(4):22-4. 